\title{
Impact of Nonpharmacological Public Health Interventions on Epidemiological Parameters of COVID-19 Pandemic in India
}

\author{
Pradip Kharya \\ All India Institute of Medical Sciences, Gorakhpur \\ Anil Ramesh Koparkar \\ All India Institute of Medical Sciences, Gorakhpur \\ Anand Mohan Dixit \\ All India Institute of Medical Sciences, Gorakhpur \\ Hari Shanker Joshi \\ All India Institute of Medical Sciences, Gorakhpur
}

Rama Shankar Rath ( $\square$ ramashankar.aiims@gmail.com )

All India Institute of Medical Sciences Gorakhpur https://orcid.org/0000-0003-4586-0525

\section{Research Article}

Keywords: Non-Pharmacological Interventions, Impact, COVID-19, India

Posted Date: April 5th, 2021

DOI: https://doi.org/10.21203/rs.3.rs-372027/v1

License: @ (i) This work is licensed under a Creative Commons Attribution 4.0 International License. Read Full License 


\section{Abstract}

Public health interventions are epidemiologically sound cost-effective methods to control the disease burden. Non-pharmacological Interventions are the only mode to control the disease in the absence of medications. To find the impact interventions on the epidemiological indicators of disease progression. This is a secondary data analysis done on COVID-19 data. Median Doubling Time and R0 were calculated for a rolling period of seven days. Interventions were scored from zero to three with the increasing level of stringency. Multivariate linear regression was performed to find the role of individual interventions on R0 and Median Doubling Time. The highest intervention score was reported in the lockdown phase which gradually decreased to lowest level of 22 . R0 values settled to a level of 1.25 and the median doubling time increased to 20 days at the end of the study. Public awareness and public health laws were found to be related to both R0 and median doubling time in the Pre-lockdown phase only. Implementation of interventions at the ground level is one of the key factors of the success of PHI. Post implementation poor effectiveness of many interventions is evident from the study. Further studies related to the sequence of interventions is required to further analyse the poor effect of interventions.

\section{Introduction}

Public Health Interventions (PHIs) promote or protect the health or prevent ill health in communities or populations. (Rychetnik $L$ et al. 2002)They are the most cost-effective and epidemiologically sound methods to tackle both communicable and non-communicable diseases. (Owen et al. 2011) From the Spanish flu pandemic in the early twentieth century to the current period, PHIs have played an important role in preventing the rapid human massacre. (Hachett et al 2007; Aledort JE et al. 2020)

The recent COVID-19 pandemic has activated the public health system of every country. Every country has started intervening the problem in the most innovative public health approaches, apart from clinical approaches. In the absence of appropriate treatment and vaccine for COVID-19, PHIs remain the only measure to tackle this pandemic. PHls like wearing masks, physical distancing, and hand washing significantly controlled the pandemic in the past.

Since its first notification in Wuhan province in China, the pandemic has spread to almost 214 countries and severely impacted human lives. (World Health organization, Situation Report, COVID 19) Many countries like New Zealand, Singapore, Sri Lanka, and Germany could contain the pandemic to a large extent with the help of PHIs. However, countries like the United States, China, Italy, and the United Kingdom could not contain the pandemic using the same interventions. In India, the COVID-19 pandemic began in late January 2020, approximately one month after the start of the pandemic in the world. (Govt. of India, 2020) The Government of India (GOI) accordingly took many steps to stop the progress of the pandemic in India.

The main objective of the study is to assess the nature and type of non-pharmacological PHIs in different phases of the COVID-19 pandemic in India and their impact on the various epidemiological indicators related to disease progression.

\section{Methods}

\section{Study type:}

This study is a secondary data analysis conducted on data collected from different sources reporting COVID-19 caseload and intervention as mentioned below.

\section{Study duration:}

The study was conducted from January 2020 to June 2020.

\section{Methodology proper:}

The required data regarding the COVID-19 pandemic was collected from the ministry of health and family welfare, govt. of India, press information bureau India. Interventions related to COVID-19 were collected from the ministry of home affairs, govt. of India website, ministry of health and family welfare, govt. of India, the press information bureau of India.

\section{Data Analysis:}

Data collected were entered in Microsoft excel 2019 and analysis was done in Microsoft excel 2019 \& Stata 12.

Classification of time periods: The whole period of the epidemic was classified into seven phases according to the interventions and caseload. The detailed method of classification was mentioned in table-1. 
Classification of interventions: The non-pharmacological PHI measures taken by the central government related to COVID-19 can be categorized to domains like those related to restriction in the office places, restriction in industry, agriculture and construction, restriction in the local transport, restriction in the interstate air transport, restriction in the out-migration, restriction in immigration, social distancing, closure of educational institutes, closure of hospitality sector, restriction of public gathering, health system preparedness, public awareness, and public health laws.

Intervention Scoring: Each intervention is scored from zero to three based on the strictness with which it was prescribed. The higher score indicates stricter intervention, whereas the lower score indicates lower intervention. The highest intervention score was thus 42 and the lowest is zero.

Analysis Proper: Various parameters like median doubling time, death rate, recovery rate, and R0 (basic reproduction number) related to disease were calculated. The median intervention score, R0, median doubling time, death rate, and recovery rate were calculated in each period. Multivariate linear regression was performed to find the impact of each intervention on the summary measures of the COVID-19 pandemic, i.e. median doubling time and R0. For this purpose, we divided the whole study period into two categories, i.e. pre-lockdown period and lockdown \& post lockdown period.

From the number of cases, the median doubling time and RO were calculated using the following formula.

Median doubling time $=\ln (2) /(\mathrm{C} 1 / \mathrm{C} 2)$

Where $\mathrm{C} 1$ is the number of cases in a given day and $\mathrm{C} 2$ is the number of cases in the previous day.

$\mathrm{R} 0=1+(\mathrm{I} * \ln (2)) / \mathrm{Td})$ where " $\mathrm{I}$ " is the infectious period and " $\mathrm{Td}$ " is the doubling time.

R0 and median doubling time was calculated using a sliding time period of seven days as mentioned by Li Q et al, 2020. Thus, and R0 was calculated from the caseload in the previous seven days.

Study definitions:

1. COVID-19 Cases: The laboratory diagnosed cases as mentioned in the ministry of health and family welfare, govt. of India.

2. COVID-19 related Deaths: A death due to COVID-19 is defined for surveillance purposes as a death resulting from a clinically compatible illness, in a probable or confirmed COVID-19 case, unless there is a clear alternative cause of death that cannot be related to COVID disease (e.g. trauma). There should be no period of complete recovery from COVID-19 between illness and death. This definition was adopted from the Govt. of India guidelines.

3. Recovered Cases: The recovered cases are the cases declared as recovered according to the govt. of India guidelines. The definition of cured changed from time to time during the COVID-19.

4. Median doubling time: Time is taken by the number of cases to double.

5. Basic Reproduction Number (R0): the average number of secondary cases generated by a single primary cases. (Delamater et al. 2019).

\section{Results}

The pandemic was started in India approximately one month after the Wuhan outbreak. The number of cases remained stagnant for one month, i.e. in February 2020, before it began to rise in the first week of March 2020. The number of COVID-19 cases along with the number of deaths rose steadily.

\section{Epidemiological features of the pandemic:}

Overall, the pandemic recovery rate increased over time from $10.0 \%$ in the early week of March 2020 to $59.1 \%$ at the end of June. However, a sudden rise in the recovered number was observed in the last week of May 2020. The death rate, on the other hand, remained on the lower side, i.e. around 3.0\%. The median doubling time of the pandemic was found to be increasing throughout the study period from 1.0 days at the start of the pandemic to almost 20 days at the end of June 2020. However, the R0 remained static at around 1.2 at the end of the study period after an initial rise in R0 observed in February and March 2020. The phase-wise representation of these summary epidemiological variables is provided in the Table-2.

Interventions \& Intervention Scores:

Page $3 / 8$ 
India started its preparedness to combat the pandemic before the detection of the 1 st case in the country. Initial preparation was related to the advisory related to the out migration from India followed by health system preparedness as surveillance. Thus, in initial phases of intervention started from controlling the source of infection followed by interventions related to the prevention of new infection and blocking the transmission. From 25th March 2020, India announced a complete lockdown followed by stepwise unlocking of the services and continue. The detailed interventions are provided in Figure-1.

Intervention scores were found to be increasing gradually till 25th March, to achieve the highest score of 42 . After the aforementioned, there was a gradual decrease in the score in the later phases of lockdown to reach a score of 22 at the end of the study period. The detailed variation of the intervention score is given in Figure-1. Phase wise variation in the median intervention score is provided in table 2.

\section{Relation Between Intervention Score and Epidemiological Features:}

Multivariate logistic regression, it was found that public awareness ( $p$-value: 0.003 ) and public health laws ( $p$-value: 0.000 ) were significantly associated with the median doubling time in the pre-lock down phase. Similarly, R0 was negatively associated with the public health laws (p-value: 0.000) and positively associated with public awareness ( $p$-value: 0.000) in the pre-lock down phase. However, the immigration restrictions, out-migration restrictions, restrictions in a public gathering, and social distancing were found statistically not related to the $\mathrm{RO}$ and median doubling time. (Table-3)

However, in the lockdown \& post lockdown era the restriction in industry, agriculture, etc. ( $p$-value: 0.000), restrictions in local transport ( $p$ value: 0.000 ), closure of places of worship ( $p$-value: 0.000$)$, were found to be negatively associated with the median doubling time, and the same were found to be positively associated with the RO. Similarly, closure of the hospitality sector was found to be negatively associated (p-value: 0.000) with the R0. The rest all the factors were found to be not significantly associated with the median doubling time and R0. (Table-3)

\section{Discussion}

The study found that proactive intervention started in the early phase of the pandemic in the country. Initially, the interventions are linked to controlling the source of infection and gradually it shifted to blocking the transmission and prevention of new infections. The median doubling time gradually increased from 1.4 days in phase one to 18.6 days in phase seven. Similarly, the recovery rate increased gradually to $64.57 \%$ in phase seven. However, R0 decreased gradually after initial fluctuations to a lower level of around 1.2 . Death rate however remained at a lower level around 3.0\% throughout the study period. Intervention scores gradually increased till the end of the march, however after this decreasing trend was observed.

The initial intervention was found to be limited to entering the infection in the country which was logically correct as the pandemic was started in the countries outside India. This was followed by the prevention of new infections and followed by blocking the transmission. However, in the latter part of March 2020, the intervention became multi-faceted with the involvement of all the sectors. A study by Pan et al. (2020) in Wuhan, China showed that the sequence of interventions in China was mainly related to controlling the source of infection and blocking the transmission routes followed by the prevention of new infections. Singapore's government interventions started were related to the screening of the cases, testing, tracing, and treating the cases followed by restriction of the flights from the other countries by the end of January. (Wong et al. 2020) Sri Lanka, which also reported a very few numbers of cases till now acted in a similar way of starting with the health system, strengthening and testing, treating and tracing of the cases, followed by the screening of the cases and restriction of entry points to the country. (Jayatilleke et al., 2020) Both the countries shared few interventions early in the period, however India failed to restrict the cases entering early in the period.

This study shows the RO values gradually decreased in these seven phases of the pandemic in India. This decreasing trend of R0 may be due to the initial availability of a large number of susceptible individuals which gradually decreased with time to settle the R0 value to a lower level. Interventions linked to decrease contact of the infected individuals with suspectable individuals. Similarly, the trend of R0 values was observed in Severe Acute Respiratory Syndrome (SARS) and Middle East Respiratory Syndrome (MERS) in the past. (Trillia A, 2020) In the current pandemic also, a study conducted by Chong YC et al. (2020) found that the trend of RO decreased over time with few peaks in between. A study by You C et al. (2020) found that the trend of the R0 decreased over time in different states of China. However, the study by Najafi et al., 2020 in the study found to have increasing R0 values after a period of decreasing trend. This increasing trend may be due to decreased stringency of the interventions in the selected province of Iran.

The median doubling time in this study was found to be increasing throughout the study period with fluctuations in phase two and phase three of the study period. This increase in median doubling time was noted after the end of phase three, which had the highest stringency score in the entire study period. The delay in the rise in doubling time is because the effect of the intervention may take some time to 
appear in the epidemiological parameters. A study by Roudrogriz et al. (2020) showed the fluctuating nature of the median doubling time when compared with the other studies. This fluctuation limited to the initial phase of the pandemic as observed in the current study. A study by Zhou et al. (2020) found that the early doubling time of countries like Thailand, Australia, Malaysia, Vietnam, the doubling time decreased whereas in countries like Italy, Belarus, and the Philippines the doubling time increase over time. However, both R0 and median doubling time related to testing and tracing strategy.

The interventions that undertook by the govt. of India reached maximum stringency level in the latter part of March 2020, i.e. in the third phase of the study. Despite the interventions, the number of cases began to rise in phase four and later in the study period. This may be related to the poor stringency of the interventions or may be due to poor screening of the cases that may lead to continued transmission in the background. In the pre-lock down phase, the relation between public awareness and public health laws were found to be significantly associated with the median doubling time. Public awareness was found to be positively associated with R0. This may be due to the fact that the implementation of public awareness activity may not have transformed into action immediately. However, implementation of the public health laws was found to be negatively associated with the R0, i.e. with strict implementation of public health laws, the R0 value decreased. No relation was observed between the factors like social distancing, immigration, out migration found not statistically significant with the R0 and MDT. This may be attributed to the fact that the short period of action of these interventions in the pre lockdown era. In the lockdown and post-lockdown period, the interventions like the restriction of industry/ agriculture and construction, restriction of local transport were found to be negatively associated with MDT and positively associated with RO. A study by Pan et al. (2020) showed that the R0 value decreased with the non-pharmacological interventions. Various modelling studies have shown the impact of the interventions on the R0. A study by Davies et al., (2020) \& Chaudhary et al. (2020) had found each individual non-pharmacological intervention had some impact on the decrease in the R0. Similar results were obtained by Lai S, 2020 in their study in China. This opposite relation between the intervention and the R0 and median doubling time may be due to the fact that the closure of the workplaces released many migrant workers who moved to their hometown which might have helped in the seeding of the COVID 19 in the general public. The impact of which was observed in terms of an increase in caseload in the states contributing to a large number of migrant workers. (Rath et al., 2020) Other interventions also remained nonsignificant in the lockdown and the post-lockdown phase, maybe because of the higher impact of the above-discussed variables.

The study is limited by the fact that the ground level stringency was not assessed during the study. Similarly, the interventions in the later phase might have varied depending upon the number of containment zones in each state. This is one of the studies which analysed the impact of the various interventions in different phases of the pandemic in the country, which accounts for the second-highest number of cases in the world.

\section{Conclusions}

Although the strict interventions were planned in the country, but the proper execution of the interventions may be a problem across the nation, that might have affected the spread of the COVID-19 pandemic in the country. Various interventions that have shown to be helpful in controlling the different parts of the world were found to be ineffective in India. Thus, further research is required pertaining to the intervention implementation strategies in epidemic situations, human behavioural pattern related to the pandemic situation may be required to further analyse the poor effectiveness of interventions as depicted by the current study.

\section{Declarations}

\section{Compliance with Ethical Standards:}

\section{Conflicts of interests: None}

2. Ethics Approval: Not Applicable as it is a secondary data analysis

3. Conflict of Interest: None

4. Consent to Participate: None

\section{Acknowledgements: None}

\section{Authors Contributions:}

Concept \& Design: RSR

Acquisition of data: RSR, PK, ARK 
Analysis \& interpretation of Data: RSR, AMD, HSJ

Drafting the Manuscript: RSR, PK, ARK

Critical revision of Content: AMD, HSJ

Statistical Analysis: RSR, PK, HSJ

\section{References}

1. Aledort, J. E., Lurie, N., Wasserman, J., \& Bozzette, S. A. (2007). Non-pharmaceutical public health interventions for pandemic influenza: an evaluation of the evidence base. BMC public health, 104, 7582-7587. DOl:https://doi.org/10.1186/1471-2458-7-208.

2. Chowdhury, R., Heng, K., Shawon, M. S. R., Goh, G., Okonofua, D., Ocho-Rosales, C., et al. Dynamic interventions to control COVID-19 pandemic: a multivariate prediction modelling study comparing 16 worldwide countries. Eur J Epidemiol. 35:389-399.

3. Cong, Y. C. (2020) A Novel Method for the Estimation of Dynamic Effective Reproductive Number (Dynamic R) in the COVID-19 Outbreak,. medRxiv., (Preprint) DOI: https://doi.org/10.1101/2020.02.22.20023267.

4. COVID-19, Report, S. World Health Organization. Available from: https://www.who.int/docs/default-source/coronaviruse/situationreports/20200802-covid-19-sitrep-195.pdf?sfvrsn=5e5da0. Accessed 08/03/2020.

5. Davies, N. G., Kucharski, A., Eggo, R. M., Gimma, A., \& Edmunds, W. J. (2020). Effects of non-pharmacological interventions on COVID19 cases, deaths and demand for hospital services in the UK: a modelling study. Lancet Public Heath. E375-E385. DOI:https://doi.org/10.1016/S2468-2667(20)30133-X.

6. Delamater, P. L., Street, E. J., Leslie, T. F., Leslie, T. F., Yang, T. Y., \& Jacobsen, K. H. (2019). Complexity of the Basic Reproduction Number (R0). Emerg Infect Dis. 2019, 25:1-4. DOI: https://doi.org/10.3201/eid2501.171901.

7. Discharge Policy of nCoV case, Ministry of Health and Family Welfare, Govt. of India. (2020). Available From: https://www.mohfw.gov.in/pdf/Corona\%20Discharge-Policy.pdf. Accessed 09/04/2020.

8. Govt. of India, Ministry pf Home Affairs. (2020). Available from:

https://www.mha.gov.in/sites/default/files/MHA\%200rder\%20restricting\%20movement\%20of\%20migrants\%20and\%20strict\%20enfo. Accessed 09/04/2020.

9. Guidance for appropriate recording of COVID-19 related deaths in India, National Centre for Disease Informatics and Research Indian Council of Medical Research, Government of India. (2020). Available from: https://ncdirindia.org/Downloads/CoD_COVID19_Guidance.pdf. Accessed 09/04/2020.

10. Hachett, R. J., Mecher, C. E., \& Lipstich, M. (2007). Public Health Interventions and Epidemic Intensity During the 1918 influenza pandemic. PNAS. 2007, 104:7582-7587. DOI: https://doi.org/10.1073/pnas.0610941104.

11. Jayatilleke, A. U., Dayarathne, S., de Silva, P., Siribaddana, P., Abeygunawardana, R. A. B., Nieveras, O., de Silva, N., \& de Silva, J. (2020). Covid-19 case forecasting model for Sri Lanka based on Stringency Index. Medrxiv. (Preprint). DOI: https://doi.org/10.1101/2020.05.20.20103887.

12. Lai, S., Ruktanonchai, N. W., Prosper, Z. L., Luo, O., Floyd, W., J.R., et al. (2020). Effect of non-pharmaceutical interventions for containing the COVID-19 outbreak in Chinadoi.org/10.1101/2020.03.03.20029843. medRxiv. (Preprint), DOI: https://doi.org/10.1101/2020.03.03.20029843.

13. Li, Q., Guan, X., Wu, P., Wang, X., Zhou, L., Tong, Y., et al. (2020). Early Transmission Dynamics in Wuhan, China of Novel CoronavirusInfected Pneumonia. N Engl J Med. 2020, 382:1199-1207. DOI: https://doi.org/10.1056/NEJMoa2001316.

14. Ministry of Health and Family Welfare, Govt. of India. (2020). Available from: http://www.mohfw.gov.in. Accessed 08/03/2020.

15. Ministry of Home Affairs, Govt. of India. (2020). Available from: http://www.mha.gov.in. Accessed 08/03/2020.

16. Muniz-Rodriguez, K., Chowell, G., Cheung, C. H., Jia, D., Lai, P., Lee, Y., Lui, M., Ofori, S. K., Roosa, K. M., Lone, S., Viboud, C., \& Fung, I. C. (2020). Doubling Time of the COVID-19 Epidemic by Chinese Province. medRxiv, (Preprint) DOI: https://doi.org/10.1101/2020.02.05.20020750.

17. Najafi, F., Izadi, N., Hashemi-Nazari, S. S., Khosravi- Shadmani, F., Nikbakht, R., \& Shakiba, E. (2020) Serial interval and time-varying reproduction number estimation for COVID-19 in western Iran. New Microbes New Infect. 2020, 36:100715. DOI: https://doi.org/10.1016/j.nmni.2020.100715.

18. Owen, L., Morgan, A., Fischer, A., Ellis, S., Hoy, A., \& Kelly, M. P. (2020). The cost-effectiveness of public health interventions. Journal of Public Health. 2011, 34:37-45. DOI: https://doi.org/10.1093/pubmed/fdr075.

Page 6/8 
19. Pan, A., Liu, L., Wang, C., Guo, H., Hao, X., Wang, Q., et al. (2020). Association of Public Health Interventions with the Epidemiology of the COVID-19 Outbreak in Wuhan, China. JAMA. 2020, 323:1915-1923. DOI: https://doi.org/10.1001/jama.2020.6130.

20. Press Information Bureau, Govt. of India. (2020). Available from: http://PressReleasePage.aspx. Accessed 08/03/2020.

21. Press Information Bureau, Govt. of India. (2020). Available from: https://www.pib.gov.in/indexd.aspx Accessed 08/03/2020.

22. Rath, R., Dixit, A. M., Koparkar, A. R., Kharya, P., \& Joshi, H. S. (2020). COVID-19 Pandemic in India: A comparison of Pandemic Pattern of Selected States. Nepal J Epidemol, 10, 856-864. DOl:https://doi.org/10.3126/nje.v10i2.28960.

23. Rychetnik, L., Frommer, M., Hawe, P., \& Shiell, A. (2002). Criteria for evaluating evidence on public health interventions. J Epidemiol Community Health, 56, 119-127. DOI:https://doi.org/10.1136/jech.56.2.119.

24. Revised Discharge Policy of COVID-19, Ministry of Health and Family Welfare, Govt. of India. (2020). [cited 2020 Sep 4], Available from: https://www.mohfw.gov.in/pdf/ReviseddischargePolicyforCOVID19.pdf. Accessed 09/04/2020.

25. Trilla, A. (2020). One world, one health: The novel coronavirus COVID-19 epidemic. Med Clin (Barc). 2020, 154:175-177. DOI: https://doi.org/10.1016/j.medcli.2020.02.001.

26. Wong, J. E. L., Leo, Y. S., \& Tan, C. C. (2020). COVID-19 in Singapore-Current Experience: Critical Global Issues That Require Attention and Action. JAMA. 2020, 323:1243-1244. DOI: https://doi.org/10.1001/jama.2020.2467.

27. You, C., Deng, Y., Hu, W., Sun, J., Lin, Q., Zhou, F., Pang, C. H., Zhang, Y., Chen, Z., \& Zhou, X. (2020). Estimation of the Time_varying Reproduction Number of COVID-19 Outbreak in China. Int J Hyg and Environ Health, 228, 1-7.

DOI:https://doi.org/10.1016/j.ijheh.2020.113555.

28. Zhou, L., Liu, J., Dong, X., McGoogan, J. M., \& Wu, Z. (2020). COVID-19 Seeding time and Doubling time model: an early epidemic risk assessment. Infect Dis Poverty, 9, 1-9. DOI:https://doi.org/10.1186/s40249-020-00685-4.

\section{Tables}

Table-1: Pandemic period classification

\begin{tabular}{|l|l|r|}
\hline Phase of Pandemic & Intervention and Case Load Classification & Time Period \\
\hline Phase-1 & Low case load and less PHIs & $21 / 01 / 20-01 / 03 / 20$ \\
\hline Phase-2 & Low case load and increasing PHIs & $02 / 03 / 20-24 / 03 / 30$ \\
\hline Phase-3 & Phase-1 of Lock Down & $25 / 03 / 20-14 / 4 / 20$ \\
\hline Phase-4 & Phase-2 of Lock Down & $15 / 4 / 20-03 / 05 / 20$ \\
\hline Phase-5 & Phase-3 of Lock Down & $04 / 05 / 20-17 / 05 / 20$ \\
\hline Phase-6 & Phase-4 of Lock Down & $18 / 05 / 20-31 / 05 / 20$ \\
\hline Phase-7 & Phase-1 of Unlocking & $01 / 06 / 20-30 / 06 / 20$ \\
\hline
\end{tabular}

Table-2: Outcome indicators related to case load in different phases

\begin{tabular}{|c|c|c|c|c|c|c|c|}
\hline & Phase-1 & Phase-2 & Phase-3 & Phase-4 & Phase-5 & Phase-6 & Phase-7 \\
\hline Time Period & $\begin{array}{c}23 / 01 / 20- \\
01 / 03 / 20\end{array}$ & $\begin{array}{c}02 / 03 / 20- \\
24 / 03 / 30\end{array}$ & $\begin{array}{c}25 / 03 / 20- \\
13 / 4 / 20\end{array}$ & $\begin{array}{c}14 / 4 / 20- \\
03 / 05 / 20\end{array}$ & $\begin{array}{c}04 / 05 / 20- \\
16 / 05 / 20\end{array}$ & $\begin{array}{c}17 / 05 / 20- \\
31 / 05 / 20\end{array}$ & $\begin{array}{c}01 / 06 / 20- \\
30 / 06 / 20\end{array}$ \\
\hline Cumulative Cases & 3 & 516 & 8833 & 30911 & 45677 & 96203 & 376305 \\
\hline $\begin{array}{c}\text { Median Doubling } \\
\text { time (in days) }\end{array}$ & 1.4 & 4.6 & 5.1 & 10.4 & 12.4 & 13.5 \\
\hline $\begin{array}{c}\text { Number of Zero } \\
\text { Growth Days }\end{array}$ & 29 & 0 & 0 & 0 & 0 & 0 \\
\hline Test Positivity Rate & NA & 3.8 & 5.0 & 3.5 & 4.1 & 6.0 \\
\hline Recovery Rate (\%) & 0.00 & 7.55 & 9.57 & 33.26 & 42.49 & 57.96 & 64.57 \\
\hline Death Rate & 0.00 & 1.93 & 3.48 & 3.26 & 3.14 & 2.76 & 3.00 \\
\hline R0 & 4.58 & 1.96 & 2.05 & 1.51 & 1.41 & 1.35 & 1.26 \\
\hline $\begin{array}{c}\text { Median } \\
\text { Intervention Score }\end{array}$ & 3 & 15 & 42 & 39 & 37 & 33 \\
\hline
\end{tabular}

Table-3: Impact of interventions on Median Doubling Time and R0 


\begin{tabular}{|c|c|c|c|c|c|c|c|c|}
\hline \multirow{3}{*}{ Intervention } & \multicolumn{4}{|c|}{ Pre-lockdown } & \multicolumn{4}{|c|}{ Lockdown \& Post-lockdown } \\
\hline & \multicolumn{2}{|c|}{$\begin{array}{l}\text { Median Doubling } \\
\text { Time }\end{array}$} & \multicolumn{2}{|c|}{ R0 } & \multicolumn{2}{|c|}{$\begin{array}{l}\text { Median Doubling } \\
\text { Time }\end{array}$} & \multicolumn{2}{|c|}{ R0 } \\
\hline & Coef. & P Value & Coef. & $\begin{array}{l}\text { P } \\
\text { Value }\end{array}$ & Coef. & P Value & Coef. & $\begin{array}{l}\mathrm{P} \\
\text { Value }\end{array}$ \\
\hline Restrictions in Offices & NA & NA & NA & NA & -1.3206 & 0.128 & 0.2480 & 0.000 \\
\hline $\begin{array}{llll}\begin{array}{l}\text { Restrictions } \\
\text { agriculture }\end{array} & \text { in } & \text { Industry } & \\
\end{array}$ & NA & NA & NA & NA & -1.6801 & 0.000 & 0.1214 & 0.000 \\
\hline Restrictions in Local Transport & NA & NA & NA & NA & -1.2769 & 0.000 & 0.0666 & 0.000 \\
\hline Interstate Air Transport & NA & NA & NA & NA & -0.1897 & 0.287 & -0.0018 & 0.884 \\
\hline Closure of Hospitality & NA & NA & NA & NA & 0.4604 & 0.081 & -0.1097 & 0.000 \\
\hline Closure of Educational institute & NA & NA & NA & NA & Removec & ue to Coll & arity & \\
\hline Restrictions in Gathering & 0.2639 & 0.271 & $-1.35 e^{-14}$ & 1.000 & Removec & ue to Coll & arity & \\
\hline Social Distancing & $2.41 \mathrm{e}-16$ & 1.000 & $\begin{array}{l}-4.49 \mathrm{e}- \\
16\end{array}$ & 1.000 & Removec & ue to Coll & arity & \\
\hline Closure of Places of Worship & -- & -- & --- & -- & -1.0622 & 0.000 & 0.0178 & 0.133 \\
\hline Immigration restrictions & -0.2983 & 0.096 & 0.0846 & 0.579 & Removec & ue to Coll & arity & \\
\hline Outmigration restrictions & 0.1196 & 0.412 & 0.0087 & 0.944 & Removec & ue to Coll & arity & \\
\hline Public Awareness & 1.0486 & 0.003 & 1.4719 & 0.000 & Removec & ue to Coll & arity & \\
\hline Public Health Laws & 0.6677 & 0.000 & \begin{tabular}{|l|}
-0.8403 \\
\end{tabular} & 0.000 & Removec & ue to Coll & arity & \\
\hline Health System preparedness & $-1.02 \mathrm{e}-16$ & 1.000 & \begin{tabular}{|l}
$-6.52 \mathrm{e}-$ \\
16 \\
\end{tabular} & 1.000 & Removec & ue to Coll & arity & \\
\hline $\mathrm{R} 2$ & 0.9102 & & 0.8378 & & 0.9477 & & 0.9245 & \\
\hline
\end{tabular}

\section{Figures}

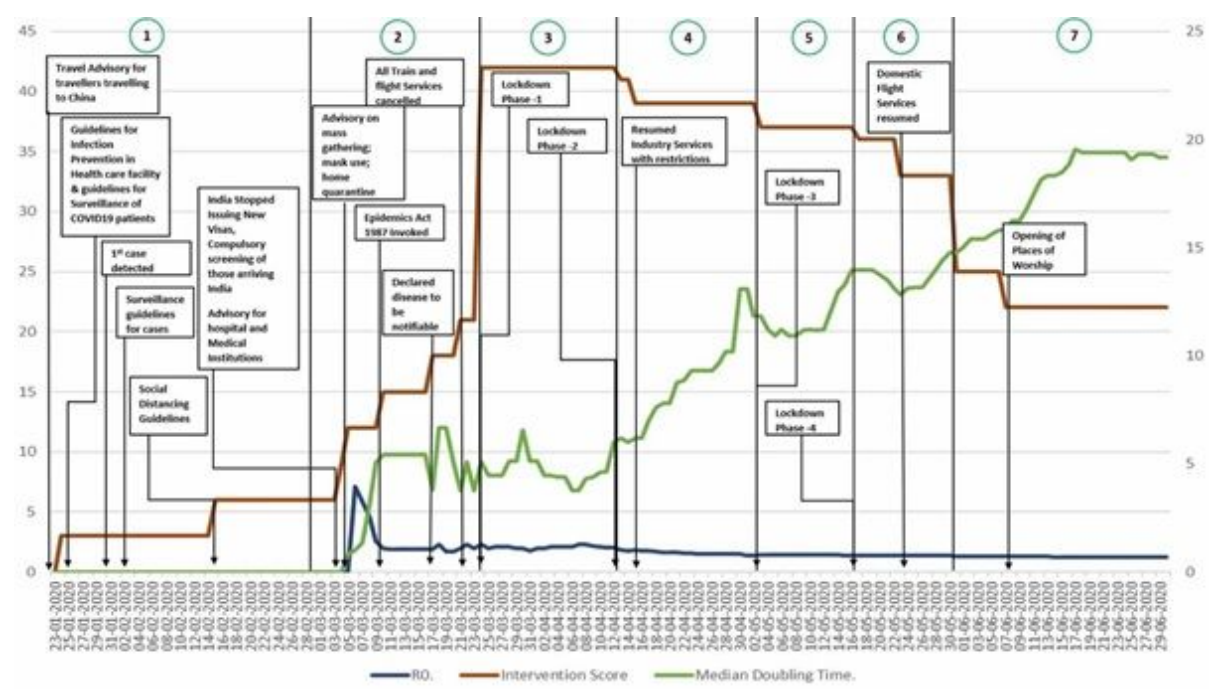

Figure 1

Non-Pharmacological Public Health Interventions with interventions cores and its impact on the R0, Median Doubling Time 